\title{
INSTRUÇÃO E MAL RADICAL EM ERIC WEIL
}

\section{Daniel Benevides Soares}

\begin{abstract}
RESUMO
O mal radical em Eric Weil compreende a suspeita a respeito das paixões: encontra-se nelas o motivo da ação? As paixões, entretanto, podem ser domesticadas. É nessa perspectiva que o mal radical se relaciona com a instrução. Para abordar essa relação, nosso estudo desenvolve um tratamento do mal, desafio para a filosofia, que em Weil tem como resposta o conceito de violência. Após situarmos o desafio do mal como violência, é possível entender no que Weil se difencia de Kant ao apresentar o conceito de mal radical. Apresentarmos brevemente a leitura de Weil do mal radical kantiano, para em seguida comparar as semelhanças e diferenças entre ambos. Encerramos apresentando o modo como a instrução pode educar as paixões.
\end{abstract}

PALAVRAS-CHAVE: Mal radical. Violência. Instrução. Paixão.

\begin{abstract}
Eric Weil's radical evil concerns suspicion about the passions: is the action's cause founds in them? Passions, however, can be domesticated. It is from this point of view that radical evil relates to instruction. To address this relationship our paper develops an treatment of, wich is an philosophy's challenge, that Weil responds with the concept of violence. After locating the challenge of evil as violence, it is possible to understand in what Weil differs from Kant in presenting the concept of radical evil. We close this study by presenting how instruction can educate the passions.
\end{abstract}

KEYWORDS: Radical evil. Violence. Iinstruction. Passion.

\section{Introdução}

A educação para Weil tem por objetivo final a autonomia de tal maneira que o indivíduo educado torne-se educador de si e dos outros. Esse processo se dá em duas etapas, a primeira delas, foco do nosso estudo, relaciona Eric Weil com o pensamento kantiano. Isso porque a instrução, primeiro passo no processo educativo weiliano, é educação das paixões, e a paixão concerne ao mal radical. Para analisar brevemente a instrução como educação das paixões em um primeiro momento é necessário compreender minimamente a resposta weiliana ao desafio do mal como violência. Feita a apresentação desse pano de fundo, é possível passar à leitura weiliana do mal radical kantiano, fonte de qual nosso autor sorve o conceito-chave do nosso estudo. Finalmente, tem-se o cenário completo para se delimitar o mal radical weiliano como violência, de modo a tornar-se compreensível a diferença do 
conceito conforme abordado por Weil em relação ao se vê na abordagem original kantiana e, então, apresentar a instrução enquanto processo educativo: a domesticação do animal no homem. ${ }^{1}$

\title{
1. O desafio do mal como violência
}

O mal frequentemente é encarado por filósofos e teólogos como um desafio sem igual $^{2}$; o que importaria, sobretudo, não seria o reconhecimento dessa constatação, mas o modo como tal problema é recebido e pensado (RICOEUR, 1988, p. 21). A resposta de Weil para esse desafio é pensá-lo sobre a forma da violência. Para Weil, esse é o problema fundamental da filosofia (CANIVEZ, 1999, p. 38), de modo que os discursos filosóficos sempre foram impelidos pelo problema da violência, ainda que com outros nomes e mesmo que os filósofos não tenham se dado conta disso (WEIL, 2012, p. 90). A violência para nosso autor é mais do que a mera agressão animal, mais do que instinto de combate dirigido aos seus congêneres (LORENZ, 1973, p. 7). A violência é outro da razão, sua negação, possibilidade que está sempre aberta para o homem:

\begin{abstract}
A razão é uma possibilidade do homem: possibilidade, isso designa o que o homem pode, e o homem pode certamente ser razoável, ao menos querer ser razoável. Mas isso é apenas uma possibilidade, não uma necessidade, e é a possibilidade de um ser que possui ao menos outra possibilidade. Sabemos que essa outra possibilidade é a violência (WEIL, 2012, p. 87, grifo do autor).
\end{abstract}

Conceber a violência como um mero dado natural de agressão equivaleria a reduzir o homem à sua pura condição empírica, o que na terminologia weiliana significa utilizar um

\footnotetext{
${ }^{1}$ A educação em Weil, no conjunto da sua proposta, inclusive na sua possível relação com as categorias da Lógica da filosofia, é estuda em ASSIS, 2016.

${ }^{2}$ A tradição filosófica compreende abordagens díspares na resposta a esse desafio. Para os estóicos, não havia uma relaidade metafísica no mal, de modo que ele era o resultado de uma falta que ocasiona uma perturbação. $\mathrm{O}$ indivíduo que comete a falta também é prejudicado pela sua ignorância, de modo que deve ser alvo de paciência. $\mathrm{O}$ indivíduo que comente a falta o faz por uma compreensão inadequada da ordem que turva o seu próprio juízo (DUHOT, 2006, p. 158 - 161). Agostinho também pode ser filiado à concepção que enxerga no mal uma desordem. Para o hiponense, o mal é uma lacuna, não apresenta substância, é a ausência de algo que deveria estar presente (GILSON; BOEHNER, 1970, p. 147). Na modernidade, Leibniz prossegue com a resposta dada ao desafio do mal no conceito da teodicéia, considerando que a origem do mal não encontra-se em Deus, mas em uma limitação conatural à todas as criaturas humanas que o pecado original tornou, então, susceptíveis de pecar (LEIBNIZ, 1983, p. 145-146). A quebra do paradigma da teodicéia como resposta ao desafio do mal chega com o grande terremoto de Lisboa no século XVIII. O Sismo desloca o mal da perspectiva da interpretação e o torna alvo de predição, como algo que deve ser evitado (NEIMAN, 2003, p. 275). Outro evento que causa uma revirada interpretativa para o problema do mal é Auschwitz: o mal para o qual não cabe justificação ou mesmo explicação adequada, aquilo que deixa o próprio pensamento em estarrecido (NEIMAN, 2003, p. 15).
}

Perspectivas - Revista do Programa de Pós-Graduação em Filosofia da UFT - n. 1 - 2019 
conceito limite de homem natural. Esse conceito limite, embora útil do ponto de vista de um expediente reflexivo, concebe o homem como separado de algo que na realidade sempre o acompanha: o processo educativo.

\begin{abstract}
A moral revela assim um conceito de homem que não é o seu, mas ao qual ela é levada por uma espécie de necessidade do seu método, o conceito de homem amoral (o que, para ela, significa: imoral porque sem moral), de homem natural. Trata-se, como acabamos de ver, de um conceito-limite: é só abstraindo da educação, vale dizer, do fato de o indivíduo pertencer sempre a uma comunidade histórica e moral (da qual ele só pode se desligar depois de ter feito parte dela), que se concebe o homem natural como uma espécie de fundo sobre o qual o ser moral se projeta para se compreender (WEIL, 2011, p. 19).
\end{abstract}

Assim, o homem sempre se vê concretamente situado em uma rede moral que o sustém, de modo que é debalde qualquer esforço para localizar em que ponto teve início a moral. ${ }^{3} \mathrm{O}$ que importa conhecer é matéria da qual brotou a moral, e esta corresponde à violência.

A moral informa o que não é moral; mas essa matéria não é sem forma, ela também não é exterior à moral ou neutra: ela é imoral e, por isso mesmo, refere-se à moral. Afinal de contas, é dela que surgiu a moral e, em última análise, é ela que se informa na moral - ela significa aqui o homem finito, determinado, ser de necessidades e desejos, violência (WEIL, 2011, p. 196-197).

A violência em Weil aparece de muitas maneiras. Ela é absurdo e negação do sentido (cf. WEIL, 2012, p. 284). Grosso modo, podemos distinguir uma violência exterior e uma violência interior, mas essa tipificação da violência pode ser alargada. ${ }^{4}$ A violência exterior, ou violência primeira, é aquela que acomete o homem fisicamente na forma, por exemplo, da enfermidade e da fome (cf. WEIL, 2011, p. 59); essa violência é também denominada mal natural (cf. WEIL, 2011, p. 82). A violência interior corresponde ao movimento das paixões, diz respeito, portanto, a vida moral do indivíduo. Particularmente interessente para nosso propósito na definição de violência interior dada por Weil (2012, p. 49) é quando o autor afirma que essa violência leva o indivíduo a praticar aquilo mesmo que reprova. Esse

\footnotetext{
3 "Seria ocioso perguntar como o homem chega a essas regras, e seria inútil buscar o começo e a origem da consciência moral. O homem enquanto ser moral, vale dizer, enquanto humano em sentido estrito, se encontra sempre provido de regras; mais ainda, ele é incapaz de se imaginar em um estado de ausência de regras: fora das regras, ele não encontra senão o animal em forma mais ou menos humana”. (WEIL, 2011, p. 21).

${ }^{4}$ Podemos, à guisa de exemplo, apresentar a distinção entre violência natural da agressão, a violência passional do desejo e da moral e por último a violência que contraria voluntariamente a lei moral e a razão (CAILOIS,1984, p.214). Podemos adiantar que o mal radical situa-se na segunda perspectiva.

Perspectivas - Revista do Programa de Pós-Graduação em Filosofia da UFT - n. 1 - 2019
} 
elemento, da ausência de certeza quanto ao que ocorre na ação moral leva a perguntar se o homem seria bom ou mal por natureza:

O homem não é naturalmente bom, mas também não é naturalmente mau; mais exatamente, quem possuísse uma ou outra dessas qualidade como se possui qualidades físicas não seria um homem, mas um animal ou um deus. $\mathrm{O}$ indivíduo deve ser conduzido ao bem, deve ser educado - e, portanto, deve poder sê-lo - para querer o bem e para evitar o mal; se abstrairmos dessa educação, ele não é nem bom nem mau, ele é, como se diz, amoral, não imoral, porque essa abstração o transforma em animal (WEIL, 2011, p. 18, grifo do autor).

Aqui entra o papel da educação, pois trata-se de um processo que visa libertar de um tipo específico de violência, que não é a exterior. A educação em Weil é um processo dado em dois níveis. Em primeiro lugar, trata-se de informar a natureza animal do homem para que ele desempenhe um papel na sociedade do trabalho. O segundo nível consiste na preparação para a liberdade razoável. Deste modo, o processo educativo em Weil consiste inicialmente na instrução e posteriormente na educação para a razão. ${ }^{5} \mathrm{O}$ propósito do nosso estudo concentra-se no primeiro nível: interessamos aqui a instrução enquanto processo de domestição dos elementos empíricos.

O objetivo da educação é agir sobre as paixões, de modo que o animal humano possa ser domesticado, fazendo com o indivíduo ocupe um lugar na comunidade, para, em seguida, educar para a razão (cf. WEIL, 2011, p. 59). A educação no contex to da sociedade incide sobre as paixões de modo que o indivíduo possa tomar seu lugar na organização do trabalho. A educação que concerne as paixões é a instrução, a primeira etapa do processo educativo (cf. WEIL, 2011, p. 97). Portanto, a instrução sobre aquilo que é da ordem do mal radical. Antes de tratarmos dessa educação das paixões e da sociedade, convém apresentarmos a noção de mal radical conforme aparece no pensamento de Weil. O termo é emprestado da filosofia kantiana. Weil faz uma apresentação desse conceito em um ensaio dos seus Problemas kantianos. Convém visitar brevemente a leitura weiliana do conceito kantiano antes de comentarmos o mal radical weiliano na sua especificidade enquanto violência.

\section{Mal radical kantiano: a leitura weiliana de um problema kantiano}

\footnotetext{
5 “Todo homem educa, queira ou não, por seu discurso e sua maneira de agir, aqueles com os quais se relaciona: todo discurso e toda ação influem sobre os outros e os formam, assim como formam o seu autor. Desse modo a realidade histórica é continuamente modificada; cada indivíduo sentindo e fazendo sentir o contraste entre sua personalidade empírica e a de outros, contribui para o estabaelicmento de regras empíricas que tornam mais fáceis a coexistência e a coloboração dos homens" (WEIL, 2011, p. 68).

Perspectivas - Revista do Programa de Pós-Graduação em Filosofia da UFT - n. 1 - 2019
} 
No caso do ser humano ter pleno controle sobre suas paixões, não haveria, então, a necessidade de imperativos: o bem seria o objeto necessário da faculdade de desejar, o que uma vontade racional haveria de querer necessariamente. E ao mal, nesse cenário, corresponderia aquilo a que se buscaria interpôr distância, o objeto necessário da faculdade de aversão: aquilo que necessariamente haveríamos de rejeitar (WEBER, 2013, p.74). "Mas o fato é que nós humanos não temos pleno controle sobre nossas inclinações e paixões" (WEBER, 2013, p.74). Aqui reside o problema do mal radical, um “[...] mal invencível de nosso coração" (KANT apud WEIL, 2012, p. 138).

Esse conceito estaria relacionado diretamente com a filosofia da religião de Kant. Entretanto, convém, antes de abordar essa perspectiva, discutir o mal radical em relação ao sistema kantiano como um todo. O mal radical, diz Weil (2012, p. 142 - 144), não poderia estar presente na fundação do conceito de dever, que precisaria ser fundado primeiro - razão pela qual tal conceito não figura explicitamente nas obras críticas, mas sim em uma metafísica moral, em uma antropologia moral-prática que pressupõe o agente enquanto livre.

O fato é que a crítica funda a moral, mas não a contém, que o imperativo categórico diz o que não se deve fazer, mas nos deixa, de maneira muito legítima, segundo Kant, na ignorância de nossos deveres positivos, os quais se determinam segundo a natureza do homem, mas de modo algum segundo a natureza de suas afecções individuais, das tradições de seu grupo, de seu temperamento, etc., mas segundo a relação dessa natureza na qualidade de simples natureza com o dever como tal (WEIL, 2012, p. 146).

Temos aqui uma relação entre natureza e dever. Com a primeira, designamos uma faculdade de desejar, de ter apetites. O dever, já sabemos que se trata da liberdade. Entre ambos existe uma ligação.

\footnotetext{
Essa ligação se efetua por meio do conceito de lei, de um imperativo categórico cuja principal característica é que não leva em conta qualquer outro fato além da existência da vontade, mais particularmente, de uma vontade que se quer livre, isto é indepedente em sua autodeterminação de todo dado que não seja o de sua natureza de vontade. Qualquer que seja a vontade de um ser finito, indigente, necessitado, isso também pertence ao domínio dos fatos: um ser infinito e, portanto, autárquico, não teria nada a desejar (WEIL, 2012, p. 146 - 147).
}

Para nosso propósito, convém ainda salientar, antes de de finalizarmos a apresentação da situação do mal radical no pensamento kantiano, que essa faculdade de desejar pode sim ter seus apetites negados pelo poder da vontade, mas ela própria não pode ser suprimida: ela é inextirpável (cf. WEIL, 2012, p. 139 - 140). Retomaremos esse ponto em breve. Por hora, retornemos ao contexto do conceito de mal radical no pensamento kantiano.

Perspectivas - Revista do Programa de Pós-Graduação em Filosofia da UFT - n. 1 - 2019 
Esse mal, resultante de “[...] nosso caráter defeituoso" (KANT apud WEIL, 2012, p. 138), segundo Weil, aparece no contexto de uma filosofia da religião kantiana, para a qual é indispensável distinguir o ensinamento auxiliar do Evangelho (milagres, revelações, veneração como meio de obtenção de favores com bajulações) do seu ensinamento fundamental: as boas intenções do coração, a vontade boa perante a invencível malignidade desse mesmo coração humano, o mal radical cujo complemento, caso se mantenha a firme convicção de alimentar com reiterada e incansável força as boas intenções, e apenas sob essa condição, pode-se confiar que seja provido por Deus, na forma de um resto de bem que não se encontra em nossas forças. Isso, diz Weil, explica a função do conceito de mal radical na filosofia da religião de Kant (cf. WEIL, 2012, p. 139 - 140). Nosso objetivo aqui, entretanto, é também apresentar-lhe o conceito segundo uma leitura weiliana. Vamos a ele.

O mal radical não se trata das próprias inclinações de nosso ser natural, em si, nem boas nem más; ele é apenas o ensejo para a ação que é moral ou não:

\begin{abstract}
A virtude é luta, não com um mal natural, mas com nossa animalidade imperdível sobre essa Terra, adversária da moralidade, se quisermos, mas adversária em um combate que confere sentido à nossa existência e que não ocorreria na ausência de um adversário que jamais se torna inimigo: a inclinação sensível forma uma tentação e, portanto, deve ser submetida à liberdade da razão-vontade; sem ela a vontade não teria campo de ação. Não é a existência da tentação que constitui a falta, é não resistir a ela (WEIL, 2012, p. 142).
\end{abstract}

Desse modo, a finitude, o desejo natural e indestrutível, são apenas tentações para a vontade humana, não coerções, de modo que aqui temos o coração do problema moral, aquilo que, segundo Weil, constitui o escândalo do mal radical: "A inclinação não é má, ela é neutra; a tentação não é irresistível; a vontade é livre - e o homem faz o mal" (WEIL, 2012, p. 148). O mal, portanto, não se trata de uma força exterior, mas está no campo da liberdade. A vontade conhece a lei da razão prática e pode obedecê-la, mas não o faz. Não se trata aqui meramente de fraqueza, mas sobretudo de auto-engano: o mal radical é engano de si mesmo, de modo que o homem, no seu foro íntimo, inverte a ordem moral: ele mente para si mesmo ao deflacionar a máxima moral em nome dos móveis do amor de si. O mal é mentira: o homem mente para si mesmo ao dizer que segue a lei moral, mas na verdade está seguindo apenas suas inclinações. A questão que surge imperiosamente é: por quê?

Segundo Weil, para compreendermos como isso ocorre, é necessário analisar os fins que o ser humano ser humano dispõe em relação as suas três disposições. São elas: as da animalidade humana enquanto ser vivo, as da humanidade enquanto ser vivo e razoável e as Perspectivas - Revista do Programa de Pós-Graduação em Filosofia da UFT - n. 1 - 2019 
da personalidade, do ser razoável e responsável. As disposições da animalidade, quando desviadas da sua finaldiade, recrudesceriam em bestialidade. A segunda classe de disposições, da humanidade, quando deturpadas, gerariam vícios da sociedade: ciúme, inveja, ingratidão; na terceira classe de disposições, é que se encontra o fundamento da possibilidade do erro, pois são elas que comandam as outras, que lhe são inferiores, o que faz com que se localize aqui a faculdade de fazer o bem. É importante salientar que todas essas disposições, em si mesmas, não são ruins, na verdade, são boas em si mesmas. $\mathrm{O}$ problema é que elas são desviadas. Isso acontece porque a terceira classe de disposições, da qual procede o uso das demais, pode errar. Se as duas primeiras disposições podem ser mal orientadas, é só a terceira que o faz. O mal é precisamente a insinceridade do coração humano que faz com que ele se engane, repetindo para si que age em nome da lei moral quando, na realidade, sua disposição de ser razoável e responsável segue, disfarçados de máximas morais, os ditames do amor de si. Eis a malignidade do coração humano: eis o mal radical (WEIL, 2012, p. 150).

Nesse ponto podemos compreender porque o mal aparece no contexto de uma filosofia da religião que fala em um Deus que proverá o Bem que faltará sempre à uma vontade que não é nunca perfeita (WEIL, 2012, p. 140). Do mal radical podemos dizer que ele é sobretudo insinceridade. E isso é fundamental porque não se trata de querer estritamente o contrário da lei moral, o que não é possível para uma vontade humana, segundo Kant. Trata-se, na verdade, de uma impureza das intenções: o indivíduo engana a si mesmo quanto a sua própria intenção, quanto aos motivos reais de sua ação. E ele o faz de tal modo que não é possível saber ao certo, mesmo para o moralista mais escrupuloso, qual foi sua motivação autêntica, se ele agiu por puro respeito a lei ou se há algum interesse oculto à sua própria consciência. O mal é insinceridade e também suspeita: nunca se saberá se a escolha foi realmente moral. E essa suspeita é tão tremenda que, para Kant, o indivíduo deve ainda conjecturar se seus bons atos não são na verdade resultado da boa fortuna, de coisas das quais não temos controle, tais como educação, temperamento condições de tempo e lugar, que situarem o indivíduo em um contexto que torna fácil agir moralmente; em outras situações, nossa segurança sobre a moralidade dos nosso atos seria ainda menor (WEIL, 2012, p. 152).

Perspectivas - Revista do Programa de Pós-Graduação em Filosofia da UFT - n. 1 - 2019 
Mal radical, portanto, significa inadequação entre vontade e lei, de modo que o ser humano é insuficiente. Ocorre o mal radical quando a perversão da máxima moral se une com a insinceridade humana. Isso é importante para compreendermos uma distinção verdadeiramente fundamental: o coração humano apresenta uma inextricável malignidade enraizada nele, mas não é essencialmente maligno, pois isso implicaria uma vontade que deliberadamente prescreveria o contrário da lei moral, o que significaria uma vontade diabólica (cf. WEIL, 2012, 151-154) o que, para Kant, permanece impossível para o ser humano.

\section{O mal radical weiliano: violência interior e instrução}

Weil reconhece a grandiosidade da contribuição de Kant para a filosofia moral. ${ }^{6}$ Não obstante, embora Weil sirva-se do termo kantiano, sua utilização com o pano de fundo da violência particulariza o conceito em relação a concepção original do filósofo de Königsberg. Dito isso, podemos compreender então as semelhanças e as distinções entre os conceitos: o indivíduo weiliano - assim como o sujeito moral kantiano - nunca está seguro de que não exista nenhum conetúdo secreto que move sua ação. Esse conteúdo, entretanto, os distingue, pois para o homem weiliano, trata-se da violência. $\mathrm{O}$ sujeito weiliano, à semelhança do kantiano, carrega o dever de agir de forma tal que o princípio de suas ações manifeste o caráter fundacional de um sistema de regras de conduta que seja coerente; perspectiva weiliana, entretanto, isso significa: não violento. Existe um imperativo moral e uma dúvida quanto ao fato de agir segundo tal imperativo. Isso é comum aos dois indivíduos:o weiliano e o kantiano. Importa para ambos saber que o preceito moral seja universalizável (cf. WEIL, 2012, p. 73). Não obstante, o modo como Weil articula o conceito de violência distingue sua abordagem do mal radical.

O indivíduo weiliano deveria submeter-se à universalidade da razão; quando o faz, entretanto, é de forma violenta. ${ }^{7}$ Isso significa que ele o faz em nome da afirmação das suas

\footnotetext{
6 "Foi necessário o trabalho de mais de vinte séculos antes que esse princípio da moral fosse enunciado na sua pureza por Kant: o indivíduo só pode considerar uma ação moralmente boa se ela procede exclusivamente de uma regra universalizável, se a máxima que a inspira não produz nem contradição nem absurdo quando transformada em regra a ser seguida por todos os homens, em todas as circunstâncias nas quais a mesma ação pode ser visada. A vontade moral é vontade razoável, não tendência natural, do indivíduo que quer ser universal. Ser moral é determinar-se pela razão, agir unicamente por respeito à lei da razão" (WEIL, 2011, p. 28).

${ }^{7}$ Sobre a relação entre educação e violência em Weil, cf. NGUYEN-DINH, 1996.

Perspectivas - Revista do Programa de Pós-Graduação em Filosofia da UFT - n. 1 - 2019
} 
paixões, do seu caráter empírico. O que pode submeter o indivíduo é a lei empírica, que entra como parte do processo de instrução. ${ }^{8}$ Aceita-se a submissão por dois motivos: ou para que o indivíduo obtenha um determinado interesse, ou simplesmente por temor (cf. WEIL, 2011, p. 55-56).

É certo que ele evitará o ato imoral. Mas como saberá que o ato realizado em conformidade com a moral procedeu, quanto à sua inspiração, de uma máxima moral? Como saberá se agiu por respeito à lei, e não por medo das consequências, por cálculo interessado, seguindo a sua natureza empírica? Ele pode querer o bem, mas nunca saberá se sua vontade foi boa (WEIL, 2011, p. 28).

A lei e o cálculo são elementos que informam a matéria da ação individual, pois a particularidade é o impulso de toda ação positiva. O princípio universal é aplicado à subjetividade empírica, sem que a reflexão moral possa arbitrar ao certo se o móvel da ação teve ou não algo de passional. Aqui aparece o mal radical weiliano como uma insegurança quanto ao fato da paixão ter ou não influenciado algum ato positivo, mesmo quando o indivíduo evita um ato imoral (WEIL, 2011, p. 28). Esse mal não pode ser desenraizado, pois o homem não pode simplesmente abrir não da sua parcela empírica. Entretanto, ele pode ser transformado (WEIL, 2011, p. 56).

O indivíduo pode, portanto, conformar-se ao universal pela lei ou pelo cálculo. Esse termo, “cálculo", é de particular interesse para nossa pesquisa. Pela atividade calculadora o indivíduo aceita conformar-se, não atender parte das reivindicações do seu ser empírico para ocupar um lugar na sociedade prevendo ganhos mais interessantes futuramente. Essa operação calculadora vincula a instrução ao mal radical, no plano da sociedade, pois é aqui que essa educação das paixões acontece. Desta feita, antes de passarmos para a o modo como a instrução transforma as paixões do ser empírico, convém conhecer onde se dá a transformação. Passemos, portanto, à sociedade.

A sociedade é uma comunidade ${ }^{9}$ organizada em vistas do trabalho, enquanto luta contra a natureza exterior, o que é o essencial na sua ótica. A sociedade prima pela eficácia e pelo cálculo racional. É bastante conhecida a definição weiliana de sociedade moderna

\footnotetext{
${ }^{8}$ Acerca da relação educação com a instrução, cf. CANIVEZ, 1985.

${ }^{9}$ A comunidade pode ser entendida como o dado de uma evolução orgânica, natural oposta às comunidade enquanto criação recente, rearranjada e artificial. A comunidade apresenta experiências de compreensão diretas, humanizadas, a sociedade é racionalista (WEIL, 2011, p. 85). A comunidade histórica dá origem à sociedade (WEIL, 2011, p. 169), que corresponde a uma organização social entendida como sistematização artificial com vistas a fins. Entra aqui a noção de cálculo e técnica de organização (WEIL, 2011, p. 167-168).

Perspectivas - Revista do Programa de Pós-Graduação em Filosofia da UFT - n. 1 - 2019
} 
como materialista, calculista e mecanicista. ${ }^{10}$ Segundo esses termos, a sociedade se apresenta para si mesma, de modo que essas definições são um espelho que a sociedade põe diante de si, o que constitui sua autoconsciência. A sociedade, por ser materialista e calculista, toma os fatores psicológicos - para o propósito do nosso estudo, podemos aqui restringir esses fatores como os interesses e desejos dos indivíduos - enquanto elementos que podem estimular ou atravancar o progresso do trabalho (WEIL, 2011, p. 85-87). ${ }^{11}$

Nesse cenário, a instrução é a parte da educação responsável por inculcar nos indivíduos os comportamentos adequados e barrar os que não o são. Esses comportamentos são estimulados de duas maneiras: pela pressão social e pelo direito. Tomemos o segundo. O direito positivo não trata das intenções, de modo que lhe é indiferente se o indivíduo apenas é moral do ponto de vista formal (WEIL, 2011, p. 46-47). O direito positivo tem uma finalidade eminentemente racional, o que se mostra de dois modos. O primeiro cumpre a função de delimitar diretamente a violência natural da individualidade empírica. O segundo é aumentar a eficácia do trabalho e da organização social. Essas funções são realizadas regrando os comportamentos daquels que participam da competição social de tal modo que práticas indesejáveis sejam banidas. Ficam interditados expedientes como a fraude, a mentira e o logro, de modo que um comportamento regular e aceitável seja estabelecido (WEIL, 2011, p. 101-102).

A instrução age sobre as paixões, domesticando a inextricável parcela animal do homem. Isso porque a individualidade - do que se ocupa a instrução - é definida por suas paixões; a paixão aparece como o único meio de educar a individualidade empírica (WEIL, 2011, p. 59). O trabalho da instrução é mostrar ao indivíduo o quanto valem os conteúdos empíricos frente à objetividade. Uma equação matemática, afirma Weil (2011, p. 61), tem validade independente de paixões e preferências. A individualidade e as paixões que a constituem, portanto, aprendem a se deixar submeter à objetividade e ao primeiro universal

\footnotetext{
${ }^{10} \mathrm{O}$ elemento calculista indica que as decisões que envolvem os processos de trabalho e suas transformações, incluindo o uso das forças disponíveis para tal se justificam com o melhor resultado obtido entre as possibilidades que se apresentem, de modo que o domínio sobre a natureza seja reforçado. O materialismo da sociedade indica que apenas fatores dessa ordem são levados em conta. Finalmente, seu mecanicismo porque todo problema é apenas problema de método do trabalho e sua organização, dizendo respeito apenas ao mecanismo de trabalho; problemas que não digam respeito ao mecanismo ou não possam ser formulados enquanto problemas de metodologia e organização são falsos problemas (WEIL, 2011, p. 87).

${ }^{11}$ Cf. Sobre essa relação, cf. SALDÍAS, 2014.

Perspectivas - Revista do Programa de Pós-Graduação em Filosofia da UFT - n. 1 - 2019
} 
que lhe é apresentado: o do trabalho e da técnica. ${ }^{12}$ Além disso, a instrução também prepara o indivíduo com conhecimentos úteis para a competição social (cf. WEIL, 2011, p. 61).

Antes de tudo, é no plano da sociedade que a universalidade se revela ao indivíduo, na forma da necessidade - para quem não quer morrer nem fugir do mundo -, exigindo dele o sacrifício do imediato do desejo e da paixão (não o sacrifício do desejo e da paixão, mas das suas formas naturais, isto é, estritamente individuais) e impulsionando-o a fazer- se reconhecer como membro útil da comunidade (WEIL, 2011, p. 97).

Tornar-se membro útil da sociedade que é a comunidade organziada em vistas do trabalho para o enfrentamento da natureza é uma demanda que pesa sobre o indivíduo. Caso ele queira ter direito aos bens que a sociedade produz, ele deve ter os conhecimentos técnicos que o tornem um membro valioso. Chegamos aqui ao âmbito da pressão social. A pressão é exercida sobre todos que participam da sociedade, exigindo que eles dominem suas paixões e a violência interior. $O$ primeiro universal aparece aqui na forma da pressão que pesa sobre todos aqueles que tomam parte no mecanismo social (WEIL, 2011, p. 102).

Levando-se em conta que individualidade é formada pelos conteúdos de uma sociedade particular, a educação não negligencia esses elementos. Ela utiliza as paixões e os valores históricos para fazer o indivíduo trabalhar, do contrário, o que poderia ocorrer seria uma rejeição do princípio do trabalho eficaz. ${ }^{13}$ "A educação social não só deve levar em conta os desejos históricos dos membros da comunidade, mas deve também manter vivos esses desejos - ao mesmo tempo que deve visar ao máximo de eficácia racional” (WEIL, 2011, p. 100).

A instrução recai sobre os sentimentos, ensinando a preteri-los em nome da objetividade. Entretanto, a educação é passível de falha e o indivíduo pode optar pela sua individualidade. O perigo aqui é que a universalidade e a objetividade sejam preteridas em nome de um jogo de sentimentalismo que, divertido para o indivíduo, torna-se infenso à sociedade. Isso porque os valores desse sentimentalismo são a individualidade - aquilo que

\footnotetext{
12 Trata-se aqui da racionalidade do trabalho social, ou seja, a universalidade formal do entendimento e do trabalho. Essa formalidade corresponde à educação formal do desejo e da paixão natural (WEIL, 2011, p. 142). Como todos os indivíduos estão sujeitos a essa demanda, $\mathrm{O}$ universal do trabalho e do entendimento forma o indivíduo para a idéia universalidade (WEIL, 2011, p. 152).

13 WEIL, 2011, p. 99-100. "O indivíduo recusa a racionalidade presente na sociedade na forma do seu próprio interesse" (CANIVEZ, 1999, p. 165).

Perspectivas - Revista do Programa de Pós-Graduação em Filosofia da UFT - n. 1 - 2019
} 
a instrução tenciona educar - e a autenticidade. ${ }^{14}$ Qualquer qualidade singular eleva o indivíduo acima da média dos outros que não são autênticos (WEIL, 2011, p. 64).

Sem dúvida, o homem de virtude média, será, frequentemente, um medíocre, e sua única qualidade consistirá em não ter qualidades estritamente pessoais. O homem superior, então, considerá-lo-á insignificante, vulgar, privado de caráter. Mas a questão é saber se o indivíduo que só é indivíduo pela ausência dessas qualidades médias é, graças a essa privação, o melhor representante da humanidade (WEIL, 2011, p. 65).

A educação pela paixão deve compreender cada individualidade sobre a qual ela se debruça, pois um tipo específico de educação que é satisfatória para uma individualidade pode soçobrar em outro conjunto mais intenso de paixões. A educação, portanto, não pode ser uniforme (WEIL, 2011, p. 65). A educação é sobre a individualidade, portanto, deve ser para cada individualidade específica. Caso seja má educação, ou seja, caso fracasse em aprimorar sensibilidade e imaginação, a educação será malfeita. É preciso, pois, apresentar esse primeiro universal adequadamente (cf. WEIL, 2011, p. 66).

Seria difícil citar o nome de um único grande homem cuja juventude tenha sido 'feliz', sem esforço e sem luta contra a pressão de um universal mal-apresentado; mas seria muito mais difícil encontrar um homem de valor que, educado para se opor ao universal concreto, tenha buscado, em lugar de realizar uma obra ou cumprir uma missão, simplesmente exprimir - não se sabe como - a sua individualidade (WEIL, 2011, p. 66).

Cumpre recordar que a educação weiliana não se conclui na instrução, pois sua finalidade última é a educação para a razão de modo que o educando torne-se educador de si mesmo e dos outros. Não obstante, caso a instrução fracasse, o segundo nível educativo não terá lugar, já que ela é condição indispensável para o segundo nível (cf. WEIL, 2011, p. 66). É preciso pois, que a instrução saiba lidar com as paixões para domesticar as paixões. Enquanto educação das paixões, a instrução não pode ser inerte.

Encontra-se por toda parte o educador inconsciente, o pedante que transmite um saber morto, ou o instrutor que inculca aptidões e atitudes parciais e particulares. São homens dessa espécie que deram má fama à educação e à tarefa do educador (WEIL, 2011, p. 66 - 67).

\footnotetext{
14 “O seu ideal não consistirá em ser originais a qualquer preço, pois isso significa, na maioria dos casos, ser falso, e dizer que dois mais dois são quatro não é nada original" (WEIL, 2011, p. 67).

Perspectivas - Revista do Programa de Pós-Graduação em Filosofia da UFT - n. 1 - 2019
} 
A instrução é educação da paixão em nome de uma objetividade, de uma primeira universalidade. Ela trabalha com a paixão para submeter a paixão. Vemos aqui mais um traço que separa Kant de Weil. Se para Kant o dever não admite exceção em relação aos móveis empíricos, para Weil a paixão pode servir à universalidade. As paixões compõe a individualidade, e convém conhecer o indivíduo que a instrução procura educar. Não há problema em servir-se das paixões; elas formam o homem, mas o homem, como as paixões, é algo que se educa.

\section{Conclusão}

O mal radical é um tema comum tanto a Kant quanto a Weil, o último resgatando o conceito do primeiro, segue tratando-o como problema moral, mas alarga sua abordagem ao situá-lo sob o pano de fundo da violência. Ao inseri-lo no campo da sociedade moderna, Weil enseja o tratamento do tema sob a perspectiva da educação. Entre ambos os autores, permanece comum a indelével a sombra da suspeita adejando sobre a ação humana: agir é uma coisa, mas se o móvel dessa ação respeitou a lei moral é uma dúvida que segue insolúvel. Há uma exigência de acordo entre a liberdade - agir pela lei moral - e o caráter empírico da individualidade, de tal modo que o segundo seja excluído como móvel da ação. Para Weil, a existência empírica é sempre dada, condicionada. Deste modo, diferindo de Kant, não existem maiores problemas se esse acordo seja sempre buscado mas nunca alcançado. Ao contrário, inserindo o desafio do mal radical no palco da sociedade, as paixões são percebidas como móvel da ação humana. Essa percepção não deve ser deplorada, mas explorada. Canalizando e cultivando as paixões, selecionam-se aquelas úteis ao processo que pode tornar o acordo entre individualidade e lei realizável. A instrução é a antessala para a morada da liberdade razoável: o universal da educação para a filosofia.

\section{REFERÊNCIAS BIBLIOGRÁFICAS}

ASSIS, F. Educação e moral: uma análise crítica da filosofia de Eric Weil. CRV: Curitiba, 2016.

CAILLOIS, R. La violence pure est-elle démoniaque? In: Actualité d'Eric Weil, Chantilly, 21-22 maio 1982. Paris, 1984. p. 53-76. 
CANIVEZ, P. Éducation et instruction d'après Eric Weil : implications sociales, politiques et morales de l'action éducative. Archives de Philosophie 48 (1985), p. 529-562.

CANIVEZ, P. Weil. Paris: Sociéte d'édition les Belles Lettres, 1999.

DUHOT, J. J. Epicteto e a sabedoria estóica. São Paulo: Edições Loyola, 2006.

GILSON, E.; BOEHNER, P. História da filosofia cristã. Petrópolis: Vozes, 1970.

LEIBNIZ, G. W. Discurso de metafísica. In: Os pensadores. São Paulo: Abril Cultural, 1983.

LORENZ, K. A agressão: uma história natural do mal. Santos (SP): Martins Fontes, 1973.

NEIMAN, S. O mal no pensamento moderno. Rio de Janeiro: DIFEL, 2003.

NGUYEN-DINH, L. Éducation ou violence selon Eric Weil. In: QUILLIEN, J. - KISCHER, G. (Orgs.), Cahiers Eric Weil V. Lille: Presses Universitaires de Lille, 1996, p. 79-86.

RICOEUR, P. O mal: um desafio à filosofia e à teologia. Campinas: Papirus, 1988.

SALDIAS, R. Cultura, Humanidades y Universidade en el pensamiento filosófico de Eric Weil. Argumentos 11 (2014), p. 98-118.

WEBER, T. Ética e filosofia do direito: autonomia e dignidade da pessoa humana. Petrópolis: Vozes, 2013.

WEIL, E. Filosofia Moral. São Paulo: É Realizações Editora, 2011.

WEIL, E. Filosofia Política. São Paulo: Loyola, 1990.

WEIL, E. Lógica da Filosofia. São Paulo: É Realizações, 2012.

WEIL, E. Problemas kantianos. São Paulo: É Realizações, 2011. 